\title{
Review \\ Adaptation of Fire-Fighting Systems to Localization of Fires in the Premises: Review
}

\author{
Geniy Kuznetsov ${ }^{1, *}$, Nikolay Kopylov ${ }^{2}$, Elena Sushkina ${ }^{2}$ and Alena Zhdanova ${ }^{3}(\mathbb{D}$ \\ 1 School of Energy and Power Engineering, National Research Tomsk Polytechnic University, \\ 634050 Tomsk, Russia \\ 2 Federal State Budgetary Establishment "All-Russian Research Institute for Fire Protection of the Ministry of \\ the Russian Federation for Civil Defence, Emergencies and Elimination of Consequences of Natural \\ Disasters", 143903 Balashikha, Russia; np.nanpb@mail.ru (N.K.); sushkina@bk.ru (E.S.) \\ 3 Research School of Physics, National Research Tomsk Polytechnic University, 634050 Tomsk, Russia; \\ zhdanovaao@tpu.ru \\ * Correspondence: kuznetsovgv@tpu.ru
}

Citation: Kuznetsov, G.; Kopylov, N.; Sushkina, E.; Zhdanova, A. Adaptation of Fire-Fighting Systems to Localization of Fires in the Premises: Review. Energies 2022, 15, 522. https://doi.org/10.3390/ en15020522

Academic Editors: Antonio Crespo and Ernesto Salzano

Received: 2 November 2021

Accepted: 5 January 2022

Published: 12 January 2022

Publisher's Note: MDPI stays neutral with regard to jurisdictional claims in published maps and institutional affiliations.

Copyright: () 2022 by the authors. Licensee MDPI, Basel, Switzerland. This article is an open access article distributed under the terms and conditions of the Creative Commons Attribution (CC BY) license (https:// creativecommons.org/licenses/by/ $4.0 /)$.

\begin{abstract}
Fire protection is a basic safety issue for all categories of buildings. The criteria for effective fire suppression and the characteristics of extinguishing systems in insulated areas depend on a combination of factors. The main influences include the type of combustible material, ambient temperature, type of spray extinguisher, air inflow and outflow conditions, and space geometry. This article analyzes the most widely used fire-extinguishing technologies in different locations. The main aspects of using the pulsed delivery technology of extinguishing liquid are considered. Based on the analysis of publications from the last decade, it is possible to develop intelligent systems for recording fires and extinguishing fires in the premises.
\end{abstract}

Keywords: fire; different purpose premises; fire detection; fire confinement; extinguishing compositions

\section{Introduction}

Despite the intensive work on the development of technologies for fire suppression and fire localization, fire-fighting in buildings and structures has been relevant for many decades (the number of such fires in the territories of the states of the world community has not decreased) [1-3]. This is due to the fact that the technologies currently in use are designed to suppress combustion regardless of the conditions under which the fires originate and spread [4-6]. Building technology is continuously evolving, so when typical fire-extinguishing systems manage to frequently localize hot spots, this results in significant collateral damage after large volumes of water (as a consequence of uniform parameters of operation of extinguishing systems regardless of the combustion conditions, the time of detection of a fire source, or the extremely excessive volume of extinguishing liquid spilled) [7-9]. This is typical for closed and isolated premises with complex plan and a combination of materials and substances, such as tunnels, warehouses, workshops, bunkers, and mobile units (ships of various uses, railway trains, etc.) [10-12]. In addition, according to existing regulations, each premises is equipped with a limited group of sensors (usually heat and smoke sensors) and atomizing elements. From experience [13-15], it is clear that these elements are effective in some case and highly ineffective in others, because their actuating speed depends on the conditions of the fires.

Water is one of the available and common flame retardants used to extinguish fires [16-18]. The use of water as an extinguishing and smoke-producing agent, has been the most common use in recent decades in the localization and elimination of fires in social and industrial facilities despite the availability of alternative extinguishing technologies (such as powder and gas [19]) [20-22]. 
Water jet and aerosol technologies for fire containment and extinction have been developed since the mid-20th century [1,2]. Traditionally, researchers and developers have identified certain advantages of using atomized water, such as the cooling of the burning surface, the reduction in the temperature of combustion products, the inhibition of pyrolysis of materials and substances supplying gases of different combustibility to an oxidation reaction zone, and the vapor-out of oxidizing water (oxygen) from the combustion zone [3]. In early works (for example, [1,2]), the size of droplets, delivery rate, and volumetric concentration of water droplets were identified as the main factors influencing the effective localization and extinction of fires. It has been established [1-3] that fire-fighting time decreases when droplets are smaller because their speed and volume concentration increases. It is emphasized that the specific values of these parameters depend on the type of combustible material [2], ambient temperature [1], space geometry, and a number of other factors.

There are generalizations of the known results of experimental and theoretical studies involved in the application of the spray-water fire-fighting technology [4], but such generalizations are complicated by many factors, both fully explored [1-3] and not yet fully investigated [4]. One of the main difficulties in generalizing and selecting specific values for extinction parameters (droplet dispersion, delivery rate and flow of liquid, mechanism and geometry of spray, volumetric droplet concentration, etc.) is the need to consider physical processes and chemical reactions inherent in different types of combustion. For example, fire extinguishing system parameters for " $\mathrm{A}$ " class fires cannot be used to effectively contain and extinguish "B" class fires [4]. Researchers [5,6] have summarized and described the results of studies on extinguishing " $\mathrm{A}$ " class (solid fuels) fires, and it has been established [5] that it is always possible to determine a critical volumetric flow of liquid below which a fire cannot be suppressed. In addition, it was shown in [5] how the quenching time decreases with increased liquid flow. The total amount of water consumed is only reduced in the first stage. When the optimum value of the flow of the extinguishing liquid is reached, the total volume of water consumed begins to exponentially increase [5]. This makes it possible to predict the optimal liquid flow in practice. The defined ranges of parameters can be highlighted for the effective extinguishing of fires from experiments: specific irrigation densities (2.9-6 L/ $\left.\mathrm{m}^{2} \mathrm{~min}[5,6]\right)$, specific volumetric concentrations of droplets $\left(0.2-2.5 \mathrm{~L} / \mathrm{m}^{3}[5]\right)$, and fluid pressure in the fire extinguishing system (7-14 bar [5,6]). However, it is also accented [5] that, for example, the specific sprinkler density significantly depends on the local space. Additionally, the evaluation of water aerosols for extinguishing the " $\mathrm{A}$ " class fire has shown that there is a significant influence of the density of the fuel sample, the growth of which leads to an increase in water consumption [5] (the type of fuel also has an influence). For example, plastics have a higher rate of water consumption for effective quenching than wood, and where soft furniture is present, water consumption significantly increases [5]. It was noted [5] that these features of fires have received too little attention in the literature to date. The cycle of research has been devoted to the application of water jets and aerosol fluxes for the localization and extinguishment of " $\mathrm{B}$ " class fires, which include flammable liquids [7-9] and vegetable oil [13-15]. For example, the efficiency of the application of atomized water has been proven [13-16] in cases of oil stove fires (statistics [13] have shown that $50 \%$ of fires in hotels and restaurants start in the kitchen and the main combustible substance is animal or vegetable oil).

It has also been established that the use of a special water additives [13] is more effective due to the chemical reactions in the extinguishing involving salts such as organic potassium salt $\left(\mathrm{CH}_{3} \mathrm{COOK}\right.$ and $\left.\mathrm{K}_{2} \mathrm{C}_{2} \mathrm{O}_{4}\right)$, non-metallic salt $\left(\mathrm{NH}_{4} \mathrm{H}_{2} \mathrm{PO}_{4}\right)$, and inorganic potassium salt $\left(\mathrm{KNO}_{3}, \mathrm{KH}_{2} \mathrm{PO}_{4}\right.$, and $\left.\mathrm{KCl}\right)$ at a $5 \%$ concentration. Studies on the fire extinguishing of flammable liquids [7-9], such as gasoline, benzene, kerosene, and alcohol, have also provided evidence of the efficiency of atomized water technology. However, as with "A" class fires, much depends on the type of combustible liquid. For example, it has been established [2] that liquids such as kerosene (which can be cooled to the point of ignition) and alcohol (which can be diluted) can be effectively extinguished by water aerosol. 
More recent studies (e.g., [7]) have indicated that aerosol efficiencies can be significantly higher when blowing droplets into the base of a fire, resulting in faster fluid evaporation and displacement by oxygen.

It was established in [8] that the distances between the flame, spray nozzle, and water flow are key extinguishing parameters. In addition, it was shown [8] that the combustion of flammable liquids (e.g., alcohol and kerosene) is often impossible to extinguish by aerosol flow at a pressure in a spray system below $0.4 \mathrm{MPa}$.

Research results on the influence of the water additives on the efficiency of use in fire localization and extinguishing are presented in $[13,17,18,20]$. For example, the most effective additives are organic and inorganic potassium salts such as $\mathrm{K}_{2} \mathrm{C}_{2} \mathrm{O}_{4}$ and $\mathrm{KNO}_{3}$ [13], carbamide [20], organic solvents such as ethanol and 1-propanol [18], and F-500 EA specialty additive (Hazard Control Technologies Inc., GA, USA) [17] as a result of physical processes and chemical reactions leading to decreases in the temperature in the combustion zone. Pre-heating water has been mentioned as a way to increase the cooling capacity of water mist [21]. It has been determined [21] that an increase in the initial temperature of atomized water of $10{ }^{\circ} \mathrm{C}$ results in a decrease in droplet evaporation time by about $11 \%$, and this increases the cooling capacity of water aerosol by $12 \%$ [21].

The influence of ambient parameters on effectiveness of aerosol fire-fighting has been actively investigated in the last few years. Researchers have investigated the effectiveness of this fire extinguishing technology in open and closed areas $[5,22,23]$. For " $A$ " class fire models, such as wooden bars, it has been established that less water is needed to extinguish in open areas [5] than in limited spaces. This is due to the fact that to cool the surface of the fire, more time is needed in closed areas due to the increased temperature in the premises [5]. Furthermore, previous research [22] where a multistage stand consisting of wooden blocks and cardboard boxes was used as a body of " $\mathrm{A}$ " class fire showed that the amount of water used is comparable to the systems using sprinkler spray nozzles following the effective use of fine-air mist. Thus, the effectiveness of aerosol fluxes in open areas depends on characteristics of the fire source.

Most researchers agree that systems based on aerosol jets of different dispersions can be extremely effective in the fire extinguishing of limited areas [15-18]. As a result, a large amount of research has been devoted to assessing the impact of natural and forced suctionand-exhaust ventilation systems on fire-fighting performance $[5,10,11]$. For example, a numerical simulation (using an example of an oil fireplace in a $12 \times 4 \times 3.5 \mathrm{~m}$ space) revealed [10] that the increase in the air flow rate of a forced smoke (ventilation) system in the range $0-75 \mathrm{~m}^{3} / \mathrm{min}$ increased the duration of extinguishing of the " $\mathrm{B}$ " class fire body from 25 to $102 \mathrm{~s}$ (i.e., by 4 times). Experimental research [11], in contrast, showed that minimum extinguishing times (for diesel fuel and ethanol in a $3 \times 3 \times 3 \mathrm{~m}$ space) were achieved with air consumption in a forced smoke system of about $22.9 \mathrm{~m}^{3} / \mathrm{min}$. Thus, it is clear that influence of ventilation can be different for premises of different purposes.

The use of so-called pulsing water mist is a promising option for aerosols nowadays $[12,23]$. Such systems provide a pulsed flow of liquid. One of their main objectives is to reduce water consumption during fire-fighting. The results of simulations [23] and experiments [12] have shown that the main challenge in using this technology is the need to determine the optimal pulse-pause ratio. Thus, experiments [12] have established that the maximum effect (the fastest decrease in the temperature of the hearth is less than $200^{\circ} \mathrm{C}$ ) can be achieved at $8 \mathrm{~s}$ of pulse and $8 \mathrm{~s}$ of pause. The extinguishing time for this time combination as found to be about $200 \mathrm{~s}$. With continuous spraying, the extinguishing time as found to be about $175 \mathrm{~s}$, but the water consumption at this approach was almost 1.8 times higher than the pulsed supply [12]. Simulation results [23] showed that an impulse water supply has no advantage (compared to continuous spraying) in extinguishing fires in open areas, but it is effective in extinguishing fires in closed spaces. The flame suppression was found to be 3 times faster at $1 \mathrm{~s}$ of pulse and $1 \mathrm{~s}$ of pause than at continuous spraying, and the amount of water consumed was more than 5 times lower [23]. 
Various models of spray nozzles are being actively developed [24-27]. Both traditional type nozzles [24-27], with optimum fire opening angle, droplet flow rate, and dispersion, and completely new designs are being engineered [28]. For example, a technology for the prevention of indoor fire using nitrogen and water mist was proposed in [28]. In addition, a combination of known fire-fighting techniques has been considered promising. For example, the authors of [29] described experiments in which the possibility of combining an acoustic wave fire extinguisher with water mist as a flame suppressant was considered. The results showed [29] that the combination of acoustic waves and water aerosol suppressed more effectively flames than each method individually.

Water aerosols can be used to efficiently contain and extinguish fires in closed areas. However, there are a wide range of factors that should be considered in the development of such fire-fighting systems: (1) the choice of extinguishing parameters (such as flow dispersion, rate of supply, liquid temperature, flow rate of liquid, spray geometry) significantly depends on the type and characteristics of the fire body and the environment [13-16]; (2) the removal of heat from the burning surface (cooling) is a main factor in extinguishing "A" class fires (solid fuels) [5,6]. It can thus be concluded that the most promising systems are the so-called intelligent fire registration and extinguishing systems.

\section{Fire Identification Systems}

Self-contained smoke detectors [30] are commonly used to detect fires, which represent the so-called first line of protection and fire warnings on a premises. The sound of detectors alerts people in the vicinity of a fire. One of the main problem with such smoke detectors is that they cannot be connected to other systems and can therefore delay appropriate fire-fighting measures [30]. To enhance the ability of smoke detectors to transmit and warn of fires, a remote application was designed [30] and programmed to make calls and notifications in the case of an emergency. It was proposed in [30] that microphone and dynamic speakers could be linked to autonomous smoke detectors in a computer program. The prototype of the proposed system [30] was developed using the smoke detectors and known software as Skype, Media Player, and Excel, but it has a longer response time and requires additional smoke detector settings [30]. It should also be noted that the proposed approach would allow for the transmission of the alarm to the special services if there are no people near the fire, which would reduce the time from fire detection to its extinguishing.

Most smoke detectors are either detected by an optical detection signal or ionization. However, some use both methods of smoke detection [31]. Figure 1 presents the ionization smoke detector scheme [31].

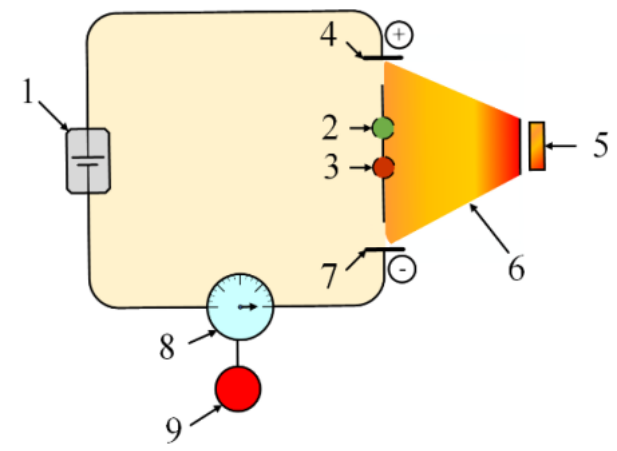

Figure 1. Ionization smoke detector scheme [31]: 1-electrical power source; 2-negative ion; 3-positive ion; 4-positive electrode; 5-alpha source; 6-alpha particles; 7-negative electrode; 8 - current detector; 9-alarm.

Ionization smoke detectors are effective in finding smoke in areas liable to rapidly spreading fires [31]. An ionization detector consists of a chamber with two current plates. Current comes from an ionization source (coil or radioactive isotope). If smoke enters the 
chamber, the tension between the plates is reduced and the fire alarm sensor is activated (the smoke absorbs alpha particles, reduces ionization, and thus interrupts the current) [31].

The light source and sensor are positioned in a photovoltaic smoke detector so that the light source does not reach the sensor. These detectors quickly react to visible smoke particles from smoldering fires, but they are less sensitive to smaller particles directly associated with the flame phase. Figure 2 illustrates the scheme of the photovoltaic smoke detector [31].

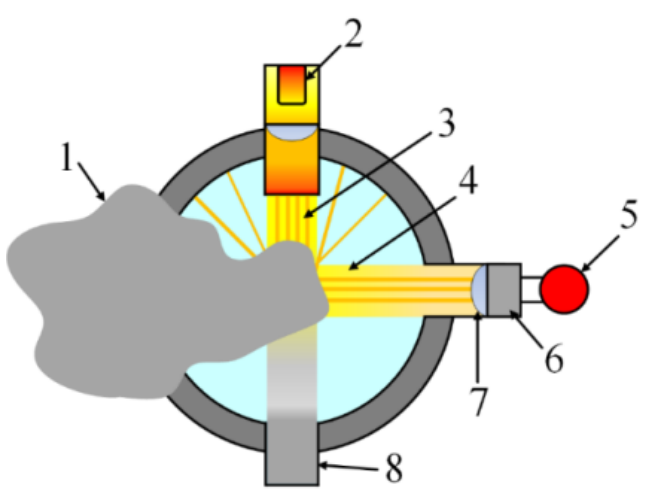

Figure 2. Scheme of the photovoltaic smoke detector [31]: 1-smoke particles; 2-light source; 3-light beam; 4-reflected light; 5-alarm; 6-photocell; 7-lens; 8-light catcher.

Photovoltaic smoke detectors use the principle of diffuse or reflected light to display visual smoke, i.e., the continuous monitoring of the optical density of the medium by the intensity of reflected IR-radiation from smoke particles. If there is smoke in the chamber, the photoelectric device, situated at right angles to the light source, switches on an alarm when it perceives light scattered by smoke particles and at a certain level of illumination [31]. To adapt the smoke detector use to different fire categories, a study was carried out on the design of a functional smoke detector based on a microcontroller and a wireless smoke detector network [30]. This wireless network [30] is used to warn of a fire and activate all the smoke detectors provided one of the detectors is activated. The proposed system [30] passed test experiments, despite some limitations of random external noise.

In addition to point alerts in the field of home security, there have been developments based on internet communication technologies [32]. The internet can be used for communication in fire detection devices. For example, IOT technology was used in [32]. The technology is directly dependent on the data transfer infrastructure that works in the specific premises. In [32], an infrastructure was built and based on Lora technology (long-range technology), LoRaWAN (public specification of the internet [32]) in particular. LoRaWAN technically complies with IOT requirements and is specifically designed for wireless data transfer on IOT premises. LoRaWAN has the advantage of low energy consumption and (as a consequence) limited data storage size. Low power consumption is suitable for residential fire safety systems and general battery operated systems. This places significant restrictions on the use of similar technologies in other types of facilities.

High-speed multi-point optical-electronic fire detection and positioning systems for fire safety in coal mines are also in development [33]. Determining the optimum number of control points and their locations on protected sites is an important step in the design of a fire-fighting system [33]. Industrial buildings tend to be large, which requires detailed work during the fire identification phase. For example, textile industry buildings [34] have several levels of fire detection (fire detection and the monitoring of fire dynamics over time). Point fire detectors with maximum differential characteristics [34] have established a linear relationship between fire factors. 
Wireless sensor network systems are also under study [35]. Such networks allow for the rapid deployment of fire detection systems, and their topologies can be easily reconfigured at an enterprise. Wireless sensor networks can be installed during building construction or its repair. The authors of [35] presented a system in which a combination of temperature and gas concentration sensors was used. An adaptive method for processing measurement resulting in a multi-sensor system, based on a Thread wireless interface, was proposed. This method adapts the system to the topology and determines not only the fact of a fire but also the position of the object (fire area).

Intelligent multi-sensor complexes [36] are also in active development for seagoing vessels. There is a set of sensors in the system for measuring temperature, carbon dioxide concentration, carbon monoxide concentration, and smoke concentration that enable the early detection of fires. For faster deployment and greater flexibility, sensors are connected using the Thread wireless interface, which allows devices to exchange data at three ISO levels. The algorithm [36] implemented in the computing unit makes a decision regarding the presence and type of ignition based on of a neural network, which continuously analyzes the information obtained from the set of sensors. The correct solution depends on the number of sensors and their location in the space. In order to optimize the location of the sensors, the authors proposed an algorithm, the function of which is the minimum time for detection of a fire.

The complexity of describing fire monitoring and containment processes in indoors makes mathematical modelling useful [37,38]. For example, the authors of [38] proposed a smoke extraction strategy depending on the scale and location of a fire in the large crosssection tunnel. It was established in [38] that the design of three-point smoke extraction openings is more effective at different scales of fire than a point-to-point tap-off scheme. In addition, the longitudinal positioning of the flaps may increase smoke extract efficiency [38], which can also reduce the number of prefabricated elements of the duct board and simplify the installation during the construction phase [38].

The timely detection of fires is a major priority. Fire safety monitoring systems are based on sensors in the vast majority of enterprises [39]. However, the operating radius of such sensors is small compared to the length of these facilities. Closed-circuit television systems comprise the predominant part of building control automation systems and are therefore based on computer vision. Fire detection systems have been developed for camera synchronization. The identification of a flame contour allows for the delineation of an ignition region. The authors of [39] proposed a new approach for the recognition of a fire from a video frame using a color correlogram function. The color probability of the adjacent pixel was evaluated using the color autocorrelogram function. With a Bayesian classifier, the proposed system could handle an image set with an accuracy of $96.97 \%$ [39].

Video-based smoke detection techniques are also offered for early warning in fire surveillance systems [40]. These algorithms are designed to detect smoke in limited spaces, both in isolated indoor premises and outdoor areas (such as storage or parking). The proposed methods use color analysis, image segmentation, stain marking, and geometric analysis to send an alarm at a specified period in real time. Using video, it is possible to detect a fire in a few seconds, and this is 15 times faster than the requirements of the Fire Alarm Standards for Industrial or Transport Systems (e.g., EN50155 standard for trains) [40].

Flame and smoke detection based on image processing is widely used when detecting fires, but due to various hazards such as blurred images, low illumination, and interference, there is always some margin of error. In such situations, it is advisable to further process and optimize fire identification results [40]. As these interferences are usually short-lived in video monitoring images, they can be eliminated by a time-smoothing algorithm. In addition, video cameras have a certain "field of vision" that requires detailed control to cover the whole territory. This shortcoming could be remedied by installing multiple cameras covering the entire space, which, in turn, would increase computing capacity. 
In the flame phase, temperature distribution is an important characteristic that can describe the phase of combustion and the dynamics of a fire. A large number of free radicals, such as $\mathrm{OH}, \mathrm{CH}$, and other intermediates, are formed during combustion. These free radicals represent the target distribution of the temperature field. They can be obtained with emission spectroscopy. The authors of [41] proposed a method based on the spectroscopy of emission of free radicals during combustion. Several functions were extracted from video images using the proposed processing scheme [41]. The elements were then post-smoothed using a time smoothing algorithm to eliminate the frequency of error detection caused by the similarity of objects between flame regions and areas not affected by combustion. A CMOS-camera with 300,000 pixels was also used to capture images in the observation area [41]. Multiple characteristics (images, motion, area velocity, roundness, number of sharp angles, shift of center of gravity, etc.) were extracted to construct a logarithmic regression to recognize a flame. The optical fiber probe selected a gas sample [41] that was transmitted to the spectrometer. Then, in real time, the portable computer recorded spectroscopic radiation signals from the internal spectrometer matrix. Figure 3 illustrates the scheme of experimental setup and its appearance.

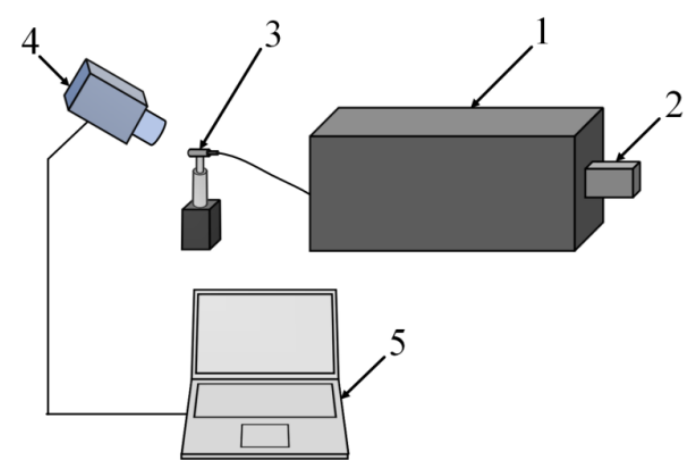

Figure 3. Scheme of hybrid experimental installation [41]: 1—spectrometer; 2-CCD; 3-fiber optic probe; 4-camera; 5-computer.

The abovementioned approaches and systems fall under the category of early detection and fire prevention in different types of premises. In addition, unmanned aerial vehicles (UAVs) are currently used in many applications because of their ability to rapidly deploy and reach difficult and dangerous locations. Despite advances in UAV autonomy and reliability, they are still remotely piloted. A new approach to autonomous indoor firefighting was proposed in [42] based on unmanned aerial vehicles; specifically, UAVs monitor and evaluate the immediate entrance to the building, monitor the UAV exterior and interior, and plan the movement of rescue workers inside the building [42].

Table 1 presents the main advantages and drawbacks of the systems regarding the new challenges of technology communication, IoT, and AI algorithms. 
Table 1. The advantages and drawbacks of the systems regarding the new challenges of technology communication, IoT, and AI algorithms.

\begin{tabular}{|c|c|c|c|}
\hline Main Parameters & Advantages & Drawbacks & References \\
\hline $\begin{array}{l}\text { Remote application. Main equipment } \\
\text { is microphone and dynamic speaker. } \\
\text { Making calls and sending messages } \\
\text { to a mobile device. }\end{array}$ & $\begin{array}{l}\text { Signal transmission to special } \\
\text { services. Reduction in response } \\
\text { time for fire suppression } \\
\text { measures. Simple setting. No } \\
\text { changes in plant smoke sensor } \\
\text { settings required. }\end{array}$ & $\begin{array}{l}\text { Need to enable buildings to } \\
\text { transmit warnings to other fire } \\
\text { safety systems. Individual } \\
\text { software development is needed }\end{array}$ & [30] \\
\hline $\begin{array}{l}\text { IOT technology, in particular } \\
\text { LoRaWAN technology. }\end{array}$ & $\begin{array}{l}\text { Wireless data transmission. Low } \\
\text { power consumption. }\end{array}$ & $\begin{array}{c}\text { Suitable only for accommodation } \\
\text { facilities. Limited size of data } \\
\text { warehouse. Accumulator battery } \\
\text { operation. }\end{array}$ & [32] \\
\hline $\begin{array}{l}\text { Adaptive method for processing } \\
\text { measurement results in a } \\
\text { multi-sensor system based on Thread } \\
\text { wireless interface. }\end{array}$ & $\begin{array}{l}\text { Easy to reconfigure the enterprise } \\
\text { topology. Possible on-site } \\
\text { installation during construction } \\
\text { and repair. Uses sensors instead } \\
\text { of detectors. }\end{array}$ & $\begin{array}{l}\text { Fire simulation is carried out with } \\
\text { the help of a fire dynamics } \\
\text { simulator at the "Polytechnic" } \\
\text { supercomputer center. }\end{array}$ & [35] \\
\hline
\end{tabular}

Set of sensors for measuring temperature, carbon dioxide concentration, carbon monoxide concentration, and smoke concentration. Thread wireless

Continuous analysis of sensor information. Optimization of sensor location in
a building.
[36]

interface (data exchange at three levels of ISO).

Video control systems based on computer vision.
Fire recognition from a video

frame using a color correlogram.
[39]

Smoke detection in limited environments, both isolated and open

areas. Colour analysis, image segmentation, stain marking, and geometric characteristic analysis.

Spectroscopy of free radicals. Possibility of temperature determination by emission spectroscopy.
Fire detection time is a few seconds.
Soft picture. Low light conditions.

Interference. Additional computing capacity is required.

\section{[40]}

Assessment of the status for

Unmanned aerial vehical (UAV).

Territory monitoring.

Assessment of the situation for open areas only.

Intelligent systems have a wide range of implementations in fire risk management [43]. For example, the authors of [44] applied mathematical modelling to accurately predict the fire resistance of the composite systems of shallow floors. The authors proposed an expert system based on machine training for the preliminary forecasting of insulation fire-resistance characteristics for shallow floor systems when exposed to a standard ignition curve-ISO 834 [44]. Additionally, [45] is noteworthy because its authors developed a system of "smart smoke control" (SSC). ANSYS Fluent commercial code contains [45] CFD simulations. Studies have found that smoke-control solutions based on the adaptive capacity of smoke-emitting fans, depending on the conditions in the protected area, may also be favorable for compartments with limited smoke container sizes. However, fullscale experiments supporting numerical model results are needed to further develop this direction. Analyses of published results [43-45] over the last two years have highlighted the prospects of software products for use in feedback systems. 


\section{Fire Suppression Systems}

Combustion is a complex physical process and chemical reaction based on rapid chemical reactions with a high amount of heat. These reactions can be interrupted by inhibiting a radical flame propagation mechanism [46]. It has been established that small particles of salt have been found to be very effective in suppressing flame propagation [46]. For example, solid fuel aerosol generators (SPAGs) [46] are capable of generating fine salt particles that can suppress radicals, thereby effectively suppressing combustion. The development of SPAGs as alternative fire extinguishing systems was described in [46]. An SPAG mainly consists of an igniter, solid fuel, cooling system, and exhaust pipe [46]. Experimental data [46] showed that this system can effectively suppress small n-heptane fires in small compartments. It was established [46] that solid fuel aerosol generators are capable of effective fire suppression. Combustion was found to stop as a result of reaction braking at an oxygen concentration higher than $17 \mathrm{vol} . \%$ in the experimental unit. It can also be noted that influence on the combustion of salt particles in the case of alkali metals was described in [47], where it was found that to improve the effectiveness of aerosol use in fire-fighting, it is necessary to increase the solid salt content of the aerosol mixture and reduce the particle size.

Reducing the risk of oil and gas explosions in industrial facilities is always an important issue. A water mist extinguishing method was tested in [48] as potentially effective to reduce explosion risks, and a series of experimental studies on large explosive casing $(1.5 \times 10 \times 1.5 \mathrm{~m}$ in size) was conducted (Figure 4$)$.

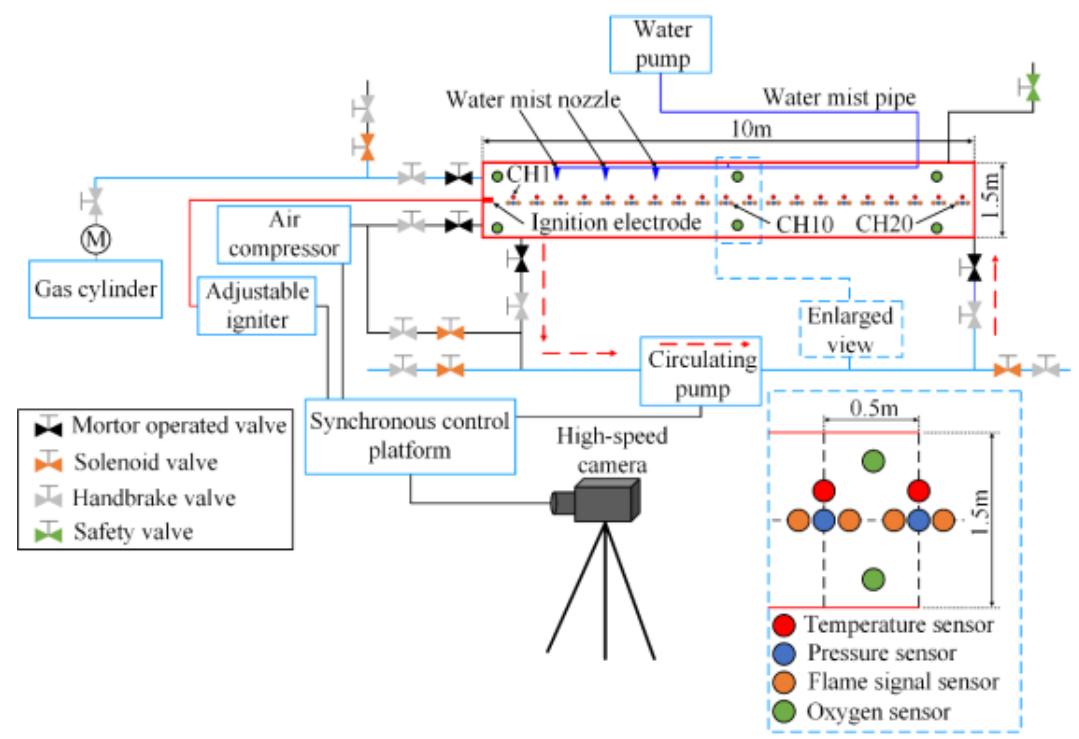

Figure 4. Scheme of the test site to establish the conditions necessary to contain an explosion during a fire under water mist extinguishing [48].

Two different types of water mist nozzles, different volumes of containers with extinguishing fluid, and different positions of nozzles and special water additives were considered. Figure 5 shows the arrangement of water mist injectors in the experimental studies [48]. Tests [48] showed that the water mist generation characteristics and the location of the nozzles had significant impacts on reduction in explosion power.

Experimental data were obtained with Phantom high-speed cameras, flame sensors, and pressure sensors. Explosion characteristics (flame propagation, flame propagation rate, excess pressure, and excess pressure build-up rate) were determined and analyzed. It was established that the water mist dispersion had a significant influence on the extinction. In addition, the use of water mist with additives could, to some extent, improve its effect on fire suppression. Water mist containing $5 \% \mathrm{~K}_{2} \mathrm{CO}_{3}$ and water mist without additives 
were found to reduce the rate of propagation of the explosion flame by $15.1 \%$ and $5.1 \%$, respectively, and excess explosion pressure by $40.8 \%$ and $15.6 \%$, respectively.

(Note: NP=Nozzle position)

Figure 5. Water mist nozzle layout in experimental studies [48].

The use of water mist and fixed-size spray water in streams is particularly relevant in fire-fighting [49-51]. However, the question of the projection of the dispersion composition of such mixtures remains. In particular, it is of interest to study the formation of gas-vapor mixtures when vapor-liquid and gas flows meet each other. In addition, the influence of the size of liquid droplets, their speed, and the speed of gases on the integral characteristics of mixing has been found to be significant. The brakeage and subsequent droplet entrainment (size from 50 to $500 \mu \mathrm{m}$ ) of polydispersion water flow by high temperature (about $1100 \mathrm{~K}$ ) gases were investigated [49-51] with optical methods such as "Particle Image Velocimetry" and "Interferometric Particle Imaging", as well as the use of cross-correlation cameras and pulse lasers. The initial speeds of water and gas droplets were found to be in the range of $0.5-5$ and $0.5-2.5 \mathrm{~m} / \mathrm{s}$, respectively. The limit ratios of initial speeds and droplet sizes at which the conditions for droplet entrainment by an oncoming gas flow were realized were established. Dimensionless criteria were introduced for the predictive assessment of stagnation conditions and subsequent water droplet entrainment by high-temperature gases under the considered conditions.

Figure 6 shows the typical videograms of polydisperse water droplets in a characteristic area of high-temperature gas mixing. Characteristic eddy formations in the mixing area at different speeds and sizes of droplets can be observed, and (due to the overlay of droplet images and tracer speeds) the trajectories of droplets are quite visible (Figure 6).

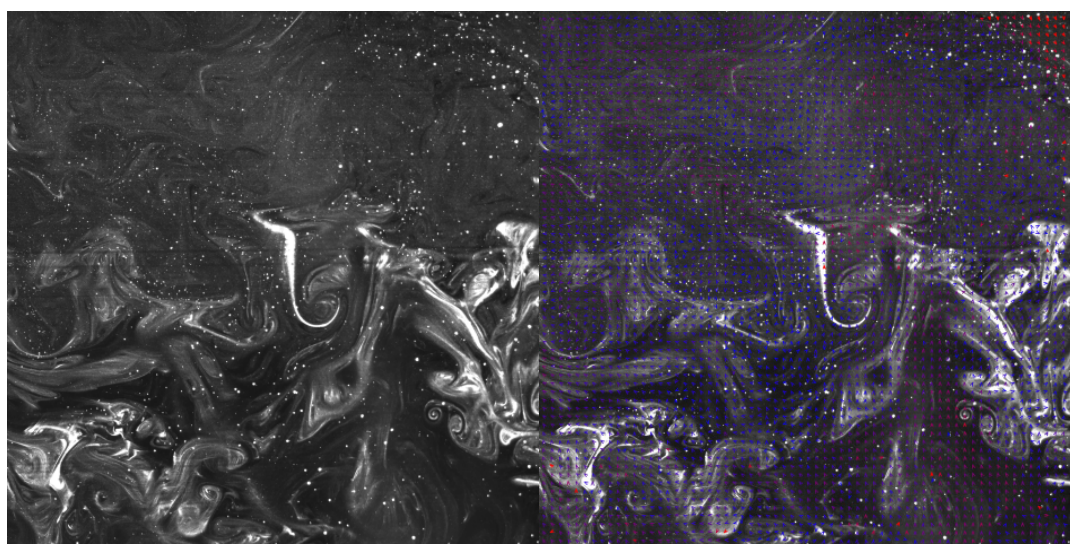

Figure 6. Typical videograms of water droplets in gas flow and trace particle velocity fields at droplet speeds $U_{\mathrm{m}}=2.5 \mathrm{~m} / \mathrm{s}$.

Figure 7 presents the $\operatorname{Re}_{\mathrm{d}}=f\left(\operatorname{Re}_{\mathrm{g}}\right)$ dependence to illustrate the areas of change in characteristics of a gas-vapor-droplet medium in which typical modes of movement of a liquid droplet body in the high-temperature gas flow are realized. For example, at parameters $\left(R_{\mathrm{m}}, U_{\mathrm{m}}\right.$, and $\left.U_{\mathrm{g}}\right)$ of a gas-vapor-droplet medium corresponding to regions above the curve given by Figure 7, the trajectory of the fluid droplets did not significantly change when mixed with high-temperature gases. The areas under $\operatorname{Re}_{\mathrm{d}}=f\left(\operatorname{Re}_{\mathrm{g}}\right)$ correspond 
to the conditions of liquid droplet entrainment by gases. At the parameters corresponding to the directly obtained $\operatorname{Re}_{\mathrm{d}}=f\left(\operatorname{Re}_{\mathrm{g}}\right)$ dependency, the droplets were characterized by the braking mode and subsequent reversal by gas flow [51].

Figure 8 presents values of $\gamma_{\mathrm{f}}$ of different initial size groups of droplets for conditions corresponding to stopping the droplets in the oncoming gas flow [49]. It is clear that at the moment of stopping, the condition was fulfilled for $\gamma_{\mathrm{f}} \rightarrow 1$. Therefore, it can be recommended that the dimensionless coefficient $\gamma_{\mathrm{f}}$, which is the ratio of the main forces acting on droplets, should be used in prediction of the braking conditions and subsequent entrainment of droplets in gas flow. It is important to note, however, that it is sufficient, in terms of the coefficient $\gamma_{f}$, to only consider the forces of gravity and resistance. As a result of experimental research $[49,50]$, the dimensionless integral criterion of $\gamma_{\mathrm{f}}$ was formulated to predict the droplet entrainment of polydisperse water flow by high-temperature gases. Representative values of $\gamma_{\mathrm{f}}$ have been established for variations in gas velocities, droplet sizes, and droplet velocities in ranges corresponding to typical gas-vapor-droplet technologies (such as water cooling in the working area of tower-coolers of thermal stations, high-temperature purification of water in power plants, defrosting of granular media with high-temperature gas-vapor fluid streams, surface treatment of various constructions with gas-vapor-droplet mixtures, and polydispersion steam fire extinguishing) $[49,50]$.

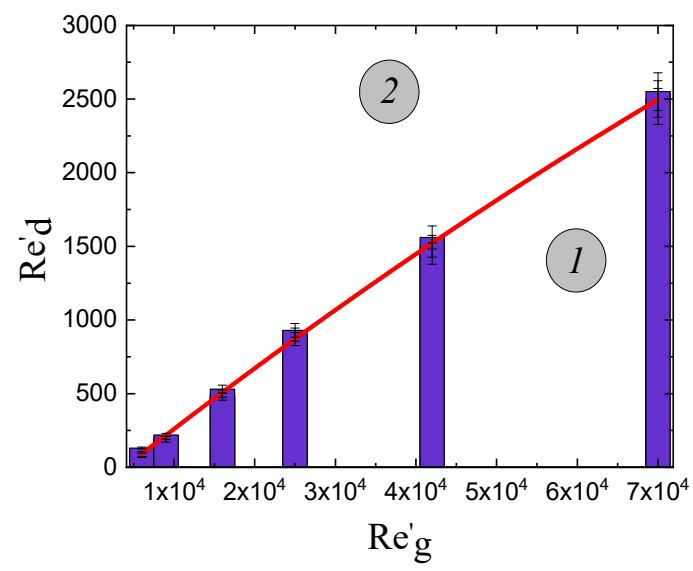

Figure 7. Typical areas of liquid droplet entrainment (1) by high-temperature gases and its unidirectional movement (2) [51].

It should be noted that efficiency of water mist use in the fire-extinguishing of combustible liquids is enhanced [52] by the addition of multi-component additives with different combustion suppression mechanisms. For example, $\mathrm{KBr}$ salt (which can reduce radicals by interrupting combustion chain reactions), surfactants, a Tween- 80 emulsifier (as an emulsifier to reduce gasification rate), and high-pressure dissolved $\mathrm{CO}_{2}$ (when water mist with dissolved $\mathrm{CO}_{2}$ gas is sprayed out of the nozzle, dissolved $\mathrm{CO}_{2}$ is released from the liquid due to pressure decay, which is an endothermic process and cooling effect) can be used [52]. Tests [52] showed that $\mathrm{KBr}$ salt mainly operated near the base of the flame and creates an unstable gap between the base of the flame and the surface of the gasoline; Tween- 80 mist and mist with dissolved $\mathrm{CO}_{2}$ reduced the flame height under test conditions. It was also found that water mist with $\mathrm{KBr}$, Tween- 80 additives, and dissolved $\mathrm{CO}_{2}$ led to significant increases in the efficiency of extinguishing combustible liquids such as gasoline [52]. 


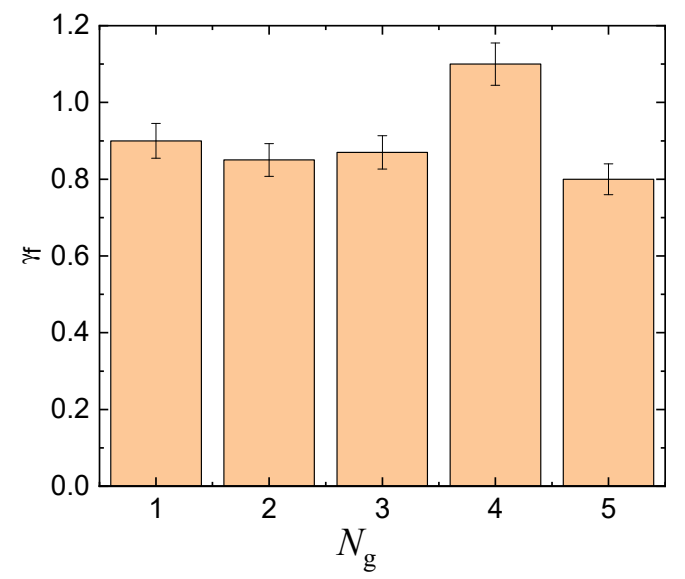

Figure 8. Ratio of droplet motion resistant forces to gravity ( $N_{\mathrm{g}}$-group number) [49]: $1-0.04 \leq R_{\mathrm{m}}$ $\leq 0.09 \mathrm{~mm} ; 2-0.09 \leq R_{\mathrm{m}} \leq 0.16 \mathrm{~mm} ; 3-0.16 \leq R_{\mathrm{m}} \leq 0.23 \mathrm{~mm} ; 4-0.23 \leq R_{\mathrm{m}} \leq 0.35 \mathrm{~mm} ; 5-0.35 \leq$ $R_{\mathrm{m}} \leq 0.50 \mathrm{~mm}$.

The issue of electric battery ignition is relevant in different areas of industry and transport [53-56]. Lithium cell combustion was described in [54]. It has been established that a fully charged component poses a risk of spontaneous combustion in the event of an electrical energy discharge. It should also be noted that it has been proposed to extinguish lithium batteries [52] with water mist and the addition of surface-active substances (SAS). It has been found that extinction time is significantly reduced when a certain percentage of the SAS is added to clean water [55]. The results of experiments showed [55] that the addition of surfactants to water mist lowered the temperature in a short time, slowed the propagation rate of the flame, and reduced the explosion intensity. The analysis of results of the studies led to a conclusion of improved extinguishing efficiency when no more than $5 \%$ of the surface-active substances are added to an extinguishing composition [55].

The spontaneous combustion of coal, caused by low-temperature oxidation, is a serious threat to coal mines (potential methane explosions) [57-60]. Current developments in coal fire prevention and extinguishment in coal mines [61-63] include the injection of gels, solutions, foam resin, and inert gas foams. However, the toxicity of the materials used and the high cost of them impose significant limitations for their widespread use in practice [57]. Spraying foam or gel into a combustion zone is one method of extinguishing fires in coal mines. The use of foam gel to prevent coal fires was investigated in [57]. In comparison to other fire-extinguishing materials, foam gel has the advantages of high stability, heat resistance, and fluidity. A foam gel is a polymer containing a blowing agent, a gelling agent, a cross linker, and water. Experiments showed that the optimum volumetric fractions of the blowing agent, gelling agent, and cross linker were $0.5 \%, 2 \%$, and $1 \%$, respectively. It was established that foam gel has a structure similar to foam, but the gel frame can maintain integrity, thereby increasing stability and heat capacity [57]. In addition, environmentally friendly fire-resistant foam with good stability was proposed in [58]; the research results showed that this flame-resistant foam was more effective than water and conventional foam in suppressing free radical formation and the reaction of the carbon-oxygen composite. At low temperatures, the effect of fire-resistant foam was found to be mainly due to physical inhibition (water evaporation cooling and insulation of coal and oxygen contact). Compared to water and normal foam, fire-resistant foam can suppress coal burning and prevent smoldering. Figure 9 shows the structure scheme of a mechanism for preventing coal burning with fire-fighting foam. 


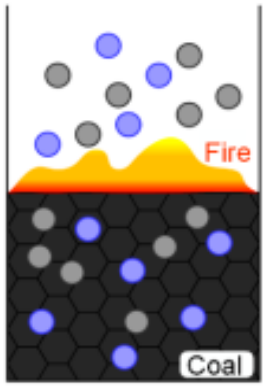

(a)

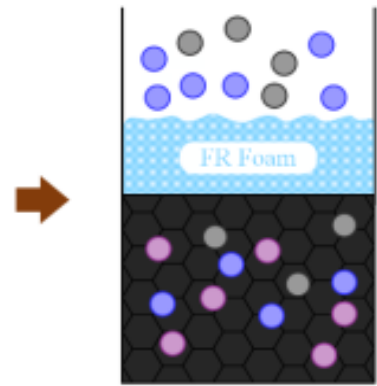

(b)
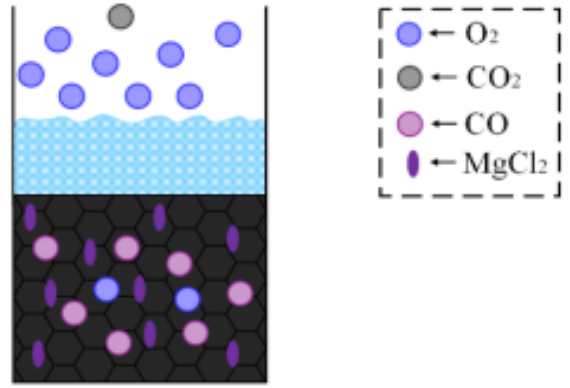

(c)

Figure 9. Schematic structure to prevent coal burning with fire-fighting foam [58]: (a) - Coal-air contact over a whole surface $\left(\mathrm{C}+\mathrm{O}_{2}=\mathrm{CO}_{2}\right) ;(\mathbf{b})$-insulation of coal from oxygen $\left(2 \mathrm{C}+\mathrm{O}_{2}=2 \mathrm{CO}\right)$ (when coal is coated with fire-resistant foam); (c) $-\mathrm{MgCl}_{2}$ solution penetrates into coal.

Coal is heavily oxidized or burned in contact with air (Figure 9a) over a whole surface $\left(\mathrm{C}+\mathrm{O}_{2}=\mathrm{CO}_{2}\right)$. When coal is coated with fire-resistant foam (Figure $\left.9 \mathrm{~b}\right)$, the insulation of coal from oxygen is realized $\left(2 \mathrm{C}+\mathrm{O}_{2}=2 \mathrm{CO}\right)$. Since the oxygen content of coal is low and cannot be replenished, the oxidation rate gradually decreases. After the fire-retardant foam has been in contact with coal for some time, a portion of the foam is destroyed and turned into an $\mathrm{MgCl}_{2}$ solution that penetrates into the coal (Figure 9c); this reduces the temperature of coal and suppresses the oxidation reaction [58].

It should be noted that use of the blowing agent (AFFF) is restricted due to the serious environmental hazard caused by the main component-fluorocarbon surface-active substances [64,65]. Five silicone surface-active substances (OFX-5211, OFX-0193, Silok2235, Silok-2232, and Tegopren-6950) were considered in [64] as key components for the preparation of fluorine-free fire-fighting foams. Results showed that fluorine-free foam could not form water film on the surface of materials regardless of the size of the spreading coefficient. Fluorine-free foam exhibited much better stability characteristics but worse spreading properties than commercial blowing AFFF agents (Figure 10).

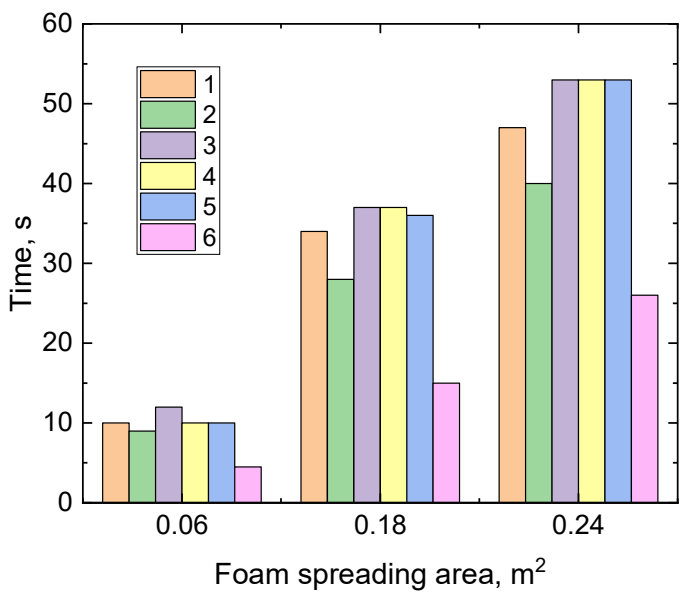

Figure 10. Change in spreading foam area according to time [64].

It was found that not all the considered fluorine-free foams containing silicone surfaceactive substances were as effective as AFFF containing fluorocarbon surface-active substances. The addition of the OFX-5211 silicone SAS alone improved the extinguishment characteristics compared to AFFF [64].

The main details of the water additives are summarized in Table 2, which, inter alia, shows the main fire-fighting localization mechanisms of water-based fire extinguishers using typical additives. 
Table 2. Influence mechanisms of typical water additives used in fire-fighting

\begin{tabular}{|c|c|c|c|c|c|c|}
\hline Room Type & Combustible Material & Water Additive & Formula & Percentage Ratio of Additive & $\begin{array}{l}\text { Thermal and Chemical Reactions during } \\
\text { Extinction }\end{array}$ & References \\
\hline \multirow{6}{*}{ Public catering facilities } & \multirow{6}{*}{ Animal and vegetable oil } & \multirow{2}{*}{ Organic potassium salt } & $\mathrm{CH}_{3} \mathrm{COOK}$ & \multirow{2}{*}{$5 \%$} & $\begin{array}{l}\text { Evaporation of alkali droplets (endothermic } \\
\text { process- cooling effect. } \\
\text { High temperatures increase fat washing rate (due } \\
\text { to glycoside's interaction with alkaline } \\
\text { solution)—-mass fraction of fuel decreases. }\end{array}$ & \multirow{2}{*}{ [13] } \\
\hline & & & $\mathrm{K}_{2} \mathrm{C}_{2} \mathrm{O}_{4}$ & & $\begin{array}{l}\text { Saponification foam is formed on the oil surface. } \\
\text { Foam has a certain thickness and } \\
\text { strength-blocking the oxidizing agent input into } \\
\text { the combustion zone. }\end{array}$ & \\
\hline & & Non-metallic salt & $\mathrm{NH}_{4} \mathrm{H}_{2} \mathrm{PO}_{4}$ & $5 \%$ & $\begin{array}{l}\text { At high temperatures, the final product of the } \\
\text { interaction between the solution and } \\
\text { high-temperature combustion products is } \\
\text { metaphoric acid, which insulates contact between } \\
\text { the combustible substance and oxygen, thus } \\
\text { blocking the input of the oxidizer into the } \\
\text { combustion zone. Metaphoric acid undergoes a } \\
\text { series of reactions at high temperatures and } \\
\text { generates a free radical-interruption of the } \\
\text { combustion process. }\end{array}$ & [13] \\
\hline & & \multirow{3}{*}{ Inorganic potassium salt } & $\mathrm{KNO}_{3}$ & \multirow{3}{*}{$5 \%$} & $\begin{array}{l}\text { Evaporation of solution droplets (endothermic } \\
\text { process) - cooling effect. } \\
\text { Evaporation of the solution generates a } \mathrm{KOH} \text { (at } \\
\text { high temperatures) that is attached to the } \\
\text { saponification. }\end{array}$ & \multirow{3}{*}{ [13] } \\
\hline & & & $\mathrm{KH}_{2} \mathrm{PO}_{4}$ & & $\begin{array}{l}\text { A film is formed on the surface of the combustible } \\
\text { substance- blocking the input of the oxidizing } \\
\text { agent into the combustion zone. }\end{array}$ & \\
\hline & & & $\mathrm{KCl}$ & & $\begin{array}{l}\text { Evaporation of solution droplets (endothermic } \\
\text { process)-cooling effect. } \\
\text { At high temperatures, the separated } \mathrm{KCl} \text { particle } \\
\text { dissociates } \mathrm{K}+\text {, which joins the chain } \\
\text { reaction-interruption of the combustion process. }\end{array}$ & \\
\hline Storage (high-risk storage) & $\begin{array}{l}\text { Wooden pallets, cardboard } \\
\text { boxes, and plastic }\end{array}$ & $\begin{array}{l}\text { Specialty Additive F-500 EA } \\
\text { (Hazard Control Technologies } \\
\text { Inc.) }\end{array}$ & & $2 \%$ & $\begin{array}{l}\text { Interaction of micelles (formed in a mixture of } \\
\text { water with additives) with a flame and } \\
\text { combustible materials - reduction in the } \\
\text { temperature of a flame burning area and a } \\
\text { combustible material. }\end{array}$ & [17] \\
\hline Industrial & n-Heptane & $\begin{array}{l}\text { Organic solvents: ethanol and } \\
\text { propanol-1 }\end{array}$ & & $\begin{array}{l}7 \text { vol. } \% \\
3 \text { vol. } \%\end{array}$ & $\begin{array}{l}\text { Intensive evaporation of extinguishing } \\
\text { solution-cooling of flame area and blocking of } \\
\text { oxidizer input into combustion area. }\end{array}$ & [18] \\
\hline
\end{tabular}


Table 2. Cont.

\begin{tabular}{|c|c|c|c|c|c|c|}
\hline Room Type & Combustible Material & Water Additive & Formula & Percentage Ratio of Additive & $\begin{array}{l}\text { Thermal and Chemical Reactions during } \\
\text { Extinction }\end{array}$ & References \\
\hline Industrial & $\begin{array}{l}\text { Flammable liquids (petrol, } \\
\text { diesel, and transformer oil) }\end{array}$ & $\begin{array}{l}\text { Organic flame retardant } \\
\text { (carbamide) }\end{array}$ & & $1 \mathrm{wt} . \%$ & $\begin{array}{l}\text { During the carbamide decomposition reaction a } \\
\text { large amount of heat is absorbed-reduction in } \\
\text { the flame temperature. } \\
\text { Flame-retardant gases }\left(\mathrm{NH}_{3} \text { and } \mathrm{CO}_{2} \text { ) are }\right. \\
\text { formed-preventing the oxidizing agent from } \\
\text { entering the combustion zone. }\end{array}$ & [20] \\
\hline Industrial & Propane & Potassium carbonate & $\mathrm{K}_{2} \mathrm{CO}_{3}$ & $5 \%$ & $\begin{array}{l}\text { K+ ions in potassium carbonate, which are } \\
\text { alkaline metal ions, participate with water } \\
\text { molecules in water mist in the interrupting the } \\
\text { chain reaction of an explosion and consume more } \\
\text { free radicals in the explosion-the effect of fire } \\
\text { suppression is increased. }\end{array}$ & [48] \\
\hline \multirow{3}{*}{ Industrial } & \multirow{3}{*}{ Petrol } & Potassium bromide & $\mathrm{KBr}$ & & $\begin{array}{l}\text { Reduction in radical concentration by interruption } \\
\text { of chain fire reactions }\end{array}$ & \multirow{3}{*}{ [52] } \\
\hline & & Polysorbate-80 (Tween-80) & & & $\begin{array}{l}\text { Used as an emulsifier to reduce the rate of } \\
\text { gasification. }\end{array}$ & \\
\hline & & Dissolved $\mathrm{CO}_{2}$ & & & $\begin{array}{l}\text { When sprayed water mist with dissolved } \mathrm{CO}_{2} \\
\text { from the nozzle, dissolved } \mathrm{CO}_{2} \text { is volatilized due } \\
\text { to loss of pressure, which is an endothermic } \\
\text { process-cooling effect. }\end{array}$ & \\
\hline Industrial & Lithium-type battery & Surface-active substance (SAS) & & Not more than $5 \%$ & $\begin{array}{l}\text { Combustion temperature is reduced due to good } \\
\text { wetting ability. }\end{array}$ & [55] \\
\hline \multirow{2}{*}{ Industrial } & \multirow{2}{*}{ n-Heptane } & $\begin{array}{l}\text { Silicone SAS OFX-5211 (key } \\
\text { component for fluorine free } \\
\text { foam) }\end{array}$ & & $3.3 \%$ & $\begin{array}{l}\text { High stability provided by hydrocarbon } \\
\text { surface-active substances and foam stabilizer } \\
\text { mixtures, as well as the rapid spread of foam } \\
\text { provided by silicone surface-active substance. }\end{array}$ & [64] \\
\hline & & AFFF & & & $\begin{array}{l}\text { The fire-extinguishing mechanism is the insulation } \\
\text { of liquid fuel from oxygen by a layer of foam and } \\
\text { aqueous film. Good fluidity properties--blocking } \\
\text { oxidizer input to combustion zone. }\end{array}$ & [64] \\
\hline
\end{tabular}




\section{Feedback Combustion Suppression Systems}

In industrial facilities with the development of technology, there has been a significant increase in the level of occupational safety and security [66]. As new technologies are introduced to the industry, the need for human intervention in fire safety systems decreases every day. Thus, errors resulting from human intervention are gradually minimized. For example, the fire safety of transformers and electrical substations of industrial facilities is an extremely important aspect of minimizing plant downtime and increasing the safety of workers. Integrated smoke/fire detection systems and internal/external fire extinguishing systems of transformers and electrical substations were identified [66] as very important. Water mist fire-fighting technology, which is a state-of-the-art robotic system that uses improved data communication and enables a system to implement preventive cooling and automatic fire-fighting in key areas, was proposed in [67].

The possibility of using an autonomous robot [68] capable of detecting a fire is under active discussion. With the help of a video camera, a robot can continuously film the environment. The peculiarity of the technology [68] is that when a fire is detected, the robot moves in the direction of fire and, when performing an additional pyrometer check, extinguishes it. The robotic system can be very effective, both in industrial facilities and the social sphere.

There has also been a focus in recent years on integrated systems that can be used in fire detection and containment, even in closed and isolated areas. For example, an architecture that consists of several sensors (sensors of flames, carbon dioxide in the air), a navigation platform (autonomous terrestrial wheeled robot), and a communication/localization network (BLE IoT network) that may be used in rescue operations or in fighting a fire in the premises was proposed in [69] (see Figure 11).

Water pistols and dredgers generally prevent the spread of fire to nearby buildings [70]. Based on an analysis of major fires at cultural heritage sites [70], it was concluded that the early registration of fires is necessary. Automatic water-based fire extinguishing systems are the most reliable, efficient, and cost-effective ways to ensure fire safety in buildings and installations [71].

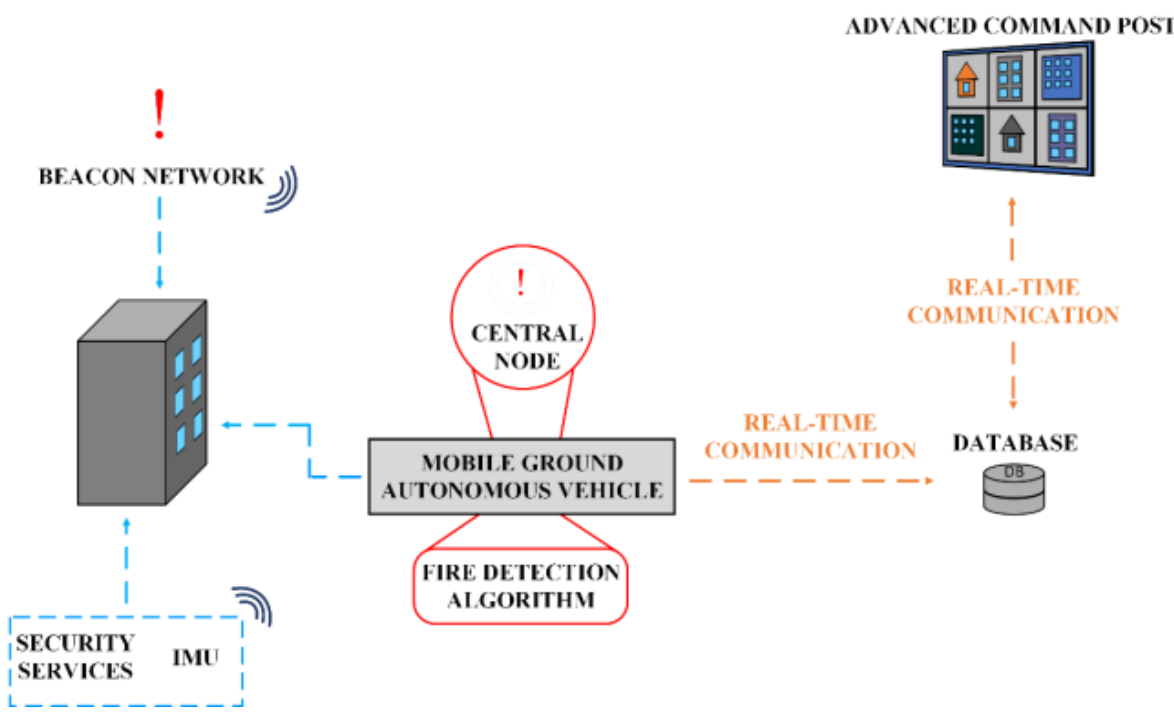

Figure 11. Model of the proposed indoor monitoring system [69].

It was proposed to automatize a fire extinguishing system with programmable logic controller (PLC) and hot reserve [72]. The proposed system consisted of three main parts-a storage reservoir for extinguishing fluid, fire pumps, and an automated distribution system. Fire pumps help to fill the reservoir and distribute water. The system had the two PLCs 
operating simultaneously, and all the network components and power supply also had backup. Figure 12 presents the structure of the proposed system.

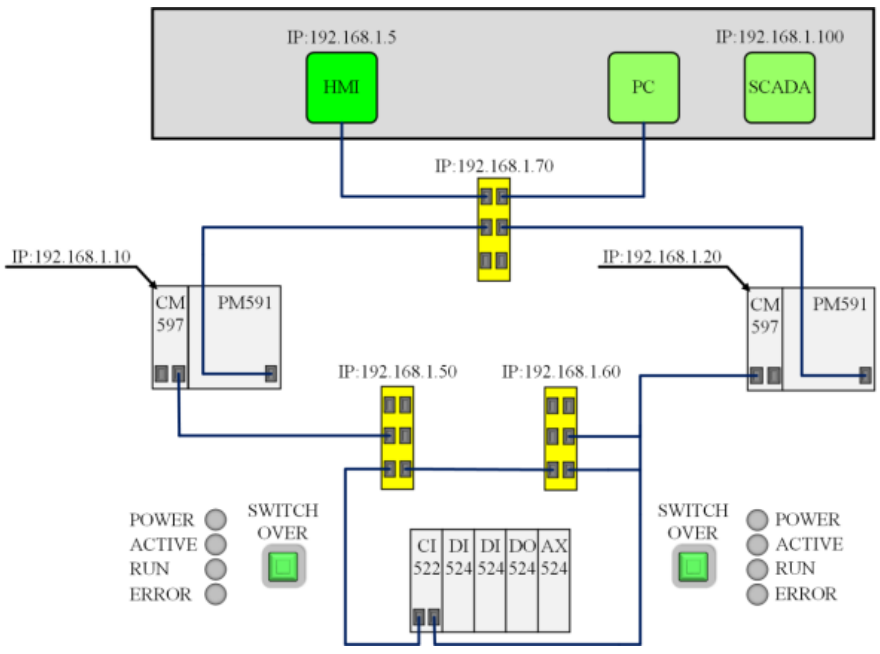

Figure 12. The structure of a fire-fighting system [72].

Water mist fire extinguishing systems have become widespread in recent years. For example, pilot studies have been carried out [73] on fire-fighting at $0.1,0.2$, and $0.3 \mathrm{~m}$ model fires with diesel fuel and heptane. It has been observed that when spray interacts with a fuel surface, there is a high probability of fuel spraying when using an upper-injection water mist system. In addition, the results of pilot studies [74] on the extinguishing of diesel fuel reservoirs with water-mist systems, under the spray-fluid conditions, through several nozzles symmetrically at the edge of the reservoir, are known (Figure 13). Experiments have shown that the predominant quenching mechanism is oxygen displacement due to the effective delivery of aerosol to the flame burning area. From the results of [74], it is possible to conclude that a water mist system can be used to extinguish fires of reservoirs with fuel liquids. Experimental parameters-the diameter of the nozzle orifice, the number and position of the nozzles (orientation angle, radial and vertical distance of the nozzle from the edge of the container), and injection pressure-were selected. The results of this research may be applied to the preliminary design of a fire-extinguishing system with an extension to fires in reservoirs with geometrical characteristics greater than those achieved in [74].

For the analysis of fire extinguishing effects using water mist with different droplet sizes, the Computational Hydrodynamics Model (CFD) and the Fire Dynamics Simulator Code (FDS) were used in [75]. The interaction of water fog and flame burning area was analyzed in detail with the help of numerical methods. The droplet size range was based on the NFPA 750 standard [75], and studies [75] have identified a range of optimal droplet sizes that provide the best extinguishing efficiency with minimum fire extinguishing time and least water discharge. However, it should be noted that there are limitations to the use of the CFD model because actual fire conditions are more complex.

A feedback fire-fighting system, based on an intelligent fire-fighting system, was proposed in [76]. The automatic detection of a fire source and continuous monitoring during the extinguishment, by adjusting the opening angle of a special infrared camera, was implemented. Based on the results of experimental studies, it was shown that after the detection of a fire by the system, the fire monitor could be deployed in the direction of fire for $2000 \mathrm{~ms}$ and the image deflection was less than 1.6 pixel. The proposed system [76] adapted to changes of ignition source position. Furthermore, after the image was iterated by no more than three frames, the controller implemented aiming, and the final deviation was less than 0.1 pixels. 


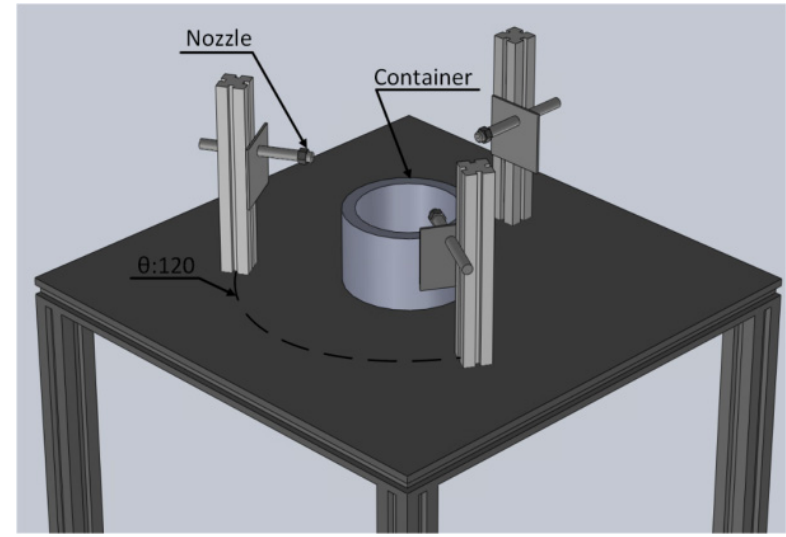

(a)

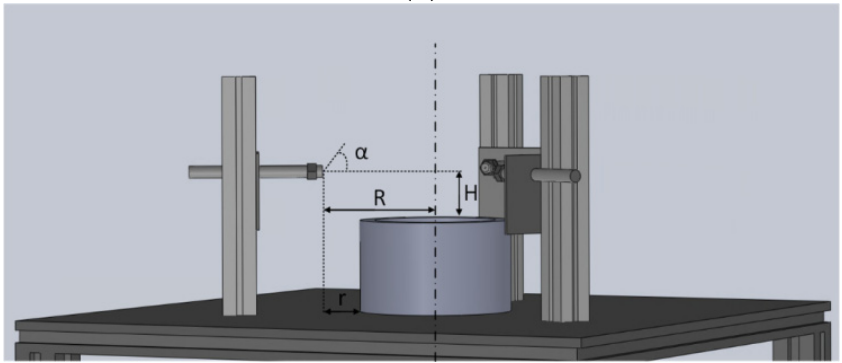

(b)

Figure 13. Experimental setup-water mist system with simultaneous use of three nozzles: (a) — enlarged view showing details of position of nozzles; (b) - isometric view [74].

The timely detection of a potential threat is a major concern in the area of fire safety. The early detection of fire source and early action can reduce the risk of major fires [77]. A faster $\mathrm{R}-\mathrm{CNN}$ model of flame detection was proposed, and experimental results demonstrated the advantages of the method, such as automatic flame characterization, the accuracy of flame detection, and the ability to generalize information about the object of observation.

High-precision real-time smoke models are important for subway tunnel fires [78]. A controllable CAERES-DNN model was proposed to predict smoke distribution in fires; the CAERES-DNN consists of the CAERES architecture (convolutional auto encoder with residual blocks) and the DNN architecture (deep neural network). The CAERES-DNN model can predict the propagation of smoke under the influence of many real-time factors in a complex subway tunnel fire with high accuracy. Predicting the propagation of smoke flows is the most important feature of fire-fighting and is vital for the development of effective fire-fighting and fire-evacuation plans [78].

It should be noted that chemical laboratories have always been considered to be hazardous areas, especially those in the pharmaceutical industry [79]. It is expected that the creation of a "watch robot" capable of taking appropriate emergency measures to detect dangerous situations, including the activation of alarms and fire-fighting, will minimize accidents and economic losses [79]. Research results have shown that, based on machine vision, the robot can identify the source of a fire and regulate the spray device to eliminate the fire. The design and use of robots in patrol laboratories can, to some extent, guarantee their fire safety [79].

\section{Current Directions of Development}

The analysis of publications of the last decade has led to the conclusion that the implementation of the feedback systems in fire management is not fully developed. The main trends in the development of fire safety systems have been aimed at minimizing the main functions of targets, directly minimizing fire elimination time, reducing the impacts of emergencies of similar nature (such as material damage, loss of life, and fire extinguishers), 
and minimum operating speeds of fire monitoring systems and fire extinguishing systems. It is also necessary to consider the specificity of a building on a case-by-case basis, but it is advisable to highlight a single approach for optimizing combustion and smoke suppression for premises with different characteristics. It is important to develop fire extinguishing systems to control the delivery of extinguishing agents (i.e., equipping fire extinguishers with so-called feedback control systems).

\section{Conclusions}

(i) An analysis of publications from the last decade in major journals showed that the use of aerosol combustion suppression technologies is relevant to fire-fighting. The main mechanisms for the influence of typical additives to water on the fire extinguishing have been established. It is possible to find an additive suitable for the type of the premises to enhance fire extinguishment.

(ii) The first fire detection line typically includes point detectors that have little inertia and are capable of detecting a fire in a relatively short time; however, complex geometry and large spaces impose significant limitations on the widespread use of such sensors in practice. State-of-the-art designs enable computer vision to identify a fire, record the presence of smoke in the premises, and continuously track the direction of smoke and flame flows. However, optical recording equipment is limited in the form of a fixed "field of vision", and it is necessary to install additional cameras in order to cover the entire area of the observed object, which entails an increase in computing capacity and the costs of establishing such systems. It seems appropriate to use a combination of cameras and point detectors (temperature, carbon dioxide, carbon monoxide, and smoke detectors) to reduce the material cost of fire detection systems and make the most efficient diagnostics possible. The possibility of using spectroscopy of free radical emission during combustion makes it possible to monitor the effectiveness of extinguishing composition action on an ignition source in real time. The use of internet communications and wireless sensor networks in the design of fire-fighting systems will enable the rapid deployment of fire detection systems and the easy reconfiguration of their topologies.

(iii) Reduction in material damage, resulting from the overcapacity of extinguishing agents, is possible with fire extinguishing systems directly adapted to the types of premises and fire parameters. The continuous control of fire factors (indoor temperature, smoke, and open flame), as well as information on the types of combustible substances in on premises, will enable a fire extinguishing system to select optimum spray parameters. The pulsed delivery of an extinguishing agent is a promising option for the use of aerosols in fire-fighting. The use of fixed intervals between feeds for a dosed supply of extinguishing fluid will reduce not only the consumption of extinguishing fluid but also material damage due to the excess supply of water or preparations.

(iv) Feedback systems are needed to minimize the main function of fire-extinguishing in premises and limited isolated areas. The continuous monitoring of the premises (temperature, smoke, flame, etc.) could allow a fire extinguishing system to adjust its fire extinguishing process (reduce/increase pressure in the quenching fluid supply system, select the optimal size of spray flow droplets, and change the duration of the quenching fluid pulse).

Author Contributions: G.K.-conceptualization, funding acquisition, and writing-original draft; N.K.- conceptualization and funding acquisition; E.S.—writing — review and editing; A.Z.-writingreview and editing. All authors have read and agreed to the published version of the manuscript.

Funding: Research was supported by Russian Science Foundation (project No 21-19-00009, https: //rscf.ru/en/project/21-19-00009/).

Conflicts of Interest: The authors declare no conflict of interest. 


\section{Nomenclature}

$\begin{array}{ll}\text { AFFF } & \text { Aqueous film-forming foam } \\ \text { BLE IoT } & \text { A communication/localization network } \\ \text { CMOS-camera } & \text { Camera for image capturing in control area } \\ \text { Faster R-CNN } & \text { Flame detection model } \\ \text { IOT } & \text { Network technology of data transfer in the building } \\ \text { PLC } & \text { Personal computer } \\ R_{\mathrm{m}} & \text { Droplet radius, } \mathrm{mm} \\ U_{\mathrm{g}} & \text { High-temperature gas flow rate, } \mathrm{m} / \mathrm{s} \\ U_{\mathrm{m}} & \text { Droplet movement rate, } \mathrm{m} / \mathrm{s} \\ \operatorname{Re}_{\mathrm{d}} & \text { Reynolds criterion for droplet } \\ \operatorname{Re}_{\mathrm{g}} & \text { Reynolds criterion for gas } \\ \gamma_{\mathrm{f}} & \text { Nondimensional coefficient for forecasting assessment of droplet entrainment } \\ & \text { of polydisperse flow by the high-temperature gases. }\end{array}$

\section{References}

1. Rasbash, D.J.; Rogowski, Z.W. Extinction of fires in liquids by cooling with water sprays. Combust. Flame 1957, 1, 453-466. [CrossRef]

2. Rasbash, D.J.; Rogowski, Z.W.; Stark, G.W.V. Mechanisms of extinction of liquid fires with water sprays. Combust. Flame 1960, 4, 223-234. [CrossRef]

3. Liu, Z.; Kim, A.K. Review of water mist fire suppression systems-Fundamental studies. J. Fire Prot. Eng. 2000, 10, 32-50. [CrossRef]

4. Liu, Z.; KIM, A.K. A Review of Water Mist Fire Suppression Technology: Part II-Application Studies. J. Fire Prot. Eng. 2001, 11, 16-42. [CrossRef]

5. Grant, G.; Brenton, J.; Drysdale, D. Fire suppression by water sprays. Prog. Energy Combust. Sci. 2000, 26, 79-130. [CrossRef]

6. Santangelo, P.E.; Jacobs, B.C.; Ren, N.; Sheffel, J.A.; Corn, M.L.; Marshall, A.W. Suppression effectiveness of water-mist sprays on accelerated wood-crib fires. Fire Saf. J. 2014, 70, 98-111. [CrossRef]

7. Ndubizu, C.C.; Ananth, R.; Tatem, P.A. Effects of droplet size and injection orientation on water mist suppression of low and high boiling point liquid pool fires. Combust. Sci. Technol. 2000, 157, 63-86. [CrossRef]

8. Xishi, W.; Guangxuan, L.; Jun, Q.; Weicheng, F. Experimental study on the effectiveness of the extinction a pool fire with water mist. J. Fire Sci. 2002, 20, 279-295. [CrossRef]

9. Qin, J.; Chow, W.K. Experimental data on water mist suppression. In Proceedings of the Procedia Engineering the 9th AsiaOceania Symposium on Fire Science and Technology, Hefei, China, 17-20 October; Elsevier Ltd.: Amsterdam, The Netherlands, 2013; Volume 62, pp. 868-877.

10. Liu, W.Y.; Chen, C.H.; Shu, Y.L.; Chen, W.T.; Shu, C.M. Fire suppression performance of water mist under diverse desmoking and ventilation conditions. Process Saf. Environ. Prot. 2020, 133, 230-242. [CrossRef]

11. Zhou, Y.; Bu, R.; Zhang, X.; Fan, C.; Gong, J. Performance evaluation of water mist fire suppression: A clean and sustainable fire-fighting technique in mechanically-ventilated place. J. Clean. Prod. 2019, 209, 1319-1331. [CrossRef]

12. Lun, P.Y.; Zhang, Q.; Li, X.K. Experimental study on the pulse water mist fire suppression system performance in a confined space. J. Braz. Soc. Mech. Sci. Eng. 2020, 42, 258. [CrossRef]

13. Zhang, T.W.; Du, Z.M.; Han, Z.Y.; Liu, K. Performance evaluation of water mist with additives in suppressing cooking oil fires based on temperature analysis. Appl. Therm. Eng. 2016, 102, 1069-1074. [CrossRef]

14. Liu, Z.; Carpenter, D.; Kim, A.K. Characteristics of large cooking oil pool fires and their extinguishment by water mist. J. Loss Prev. Process Ind. 2006, 19, 516-526. [CrossRef]

15. Liu, Z.; Carpenter, D.; Kim, A. Application of Water Mist to Extinguish Large Oil Pool Fires for Industrial Oil Cooker Protection Fire Saf. Sci. 2005, 8, 741-752. [CrossRef]

16. Liu, Z.; Kim, A.K.; Carpenter, D.; Kanabus-Kaminska, J.M.; Yen, P.L. Extinguishment of cooking oil fires by water mist fire suppression systems. Fire Technol. 2004, 40, 309-333. [CrossRef]

17. Santangelo, P.E.; Tartarini, P. Full-scale experiments of fire suppression in high-hazard storages: A temperature-based analysis of water-mist systems. Appl. Therm. Eng. 2012, 45-46, 99-107. [CrossRef]

18. Koshiba, Y.; Yamamoto, Y.; Ohtani, H. Fire suppression efficiency of water mists containing organic solvents. J. Loss Prev. Process Ind. 2019, 62, 103973. [CrossRef]

19. Kim, Y.H.; Lee, M.; Hwang, I.J.; Kim, Y.J. Noise reduction of an extinguishing nozzle using the response surface method. Energies 2019, 12, 4346. [CrossRef]

20. Lu, J.; Liang, P.; Chen, B.; Wu, C.; Zhou, T. Investigation of the Fire-Extinguishing Performance of Water Mist with Various Additives on Typical Pool Fires. Combust. Sci. Technol. 2019, 192, 592-609. [CrossRef]

21. Omidvar, A.; Mahdavi, A.; Mehryar, R. A simulated study on the effect of water temperature on cooling efficiency of water mist fire extinguishers. J. Therm. Eng. 2020, 6, 460-473. [CrossRef] 
22. Yu, H.-Z.; Liu, X. An Efficacy Evaluation of Water Mist Protection Against Solid Combustible Fires in Open Environment. Fire Technol. 2019, 55, 343-361. [CrossRef]

23. Lin, Z.; Bu, R.; Zhao, J.; Zhou, Y. Numerical investigation on fire-extinguishing performance using pulsed water mist in open and confined spaces. Case Stud. Therm. Eng. 2019, 13, 100402. [CrossRef]

24. Shrigondekar, H.; Chowdhury, A.; Prabhu, S.V. Characterization of a simplex water mist nozzle and its performance in extinguishing liquid pool fire. Exp. Therm. Fluid Sci. 2018, 93, 441-455. [CrossRef]

25. Zhou, L.; Helun, L.; Li, D.; Yong, Z. Knapsack Water Mist Fire Extinguishing Device. Patent Number CN210543000, 19 May 2020.

26. Wu, S. Aerosol Spray Nozzle. Patent Number CN210494998, 12 May 2020.

27. Wu, Z. Movable water mist fire extinguishing device. Patent Number CN210409317, 28 April 2020.

28. Shi, J.; Ren, W.; Liu, X. Novel technology for fire suppression using nitrogen-water mist in enclosed spaces. Geomat. Nat. Hazards Risk 2020, 11, 22-39. [CrossRef]

29. Friedman, A.N.; Danis, P.I.; Fiola, G.J.; Barnes, C.A.; Stoliarov, S.I. Acoustically Enhanced Water Mist Suppression of Heptane Fueled Flames. Fire Technol. 2018, 54, 1829-1840. [CrossRef]

30. Ayyubi, S.; Miao, Y.; Shi, H. Automating standalone smoke alarms for early remote notifications. In Proceedings of the 201413 th International Conference on Control Automation Robotics and Vision, ICARCV 2014, Singapore, 10-12 December 2014; Institute of Electrical and Electronics Engineers Inc.: Piscataway, NJ, USA, 2014; pp. 675-680.

31. Lipu, M.S.H.; Karim, T.F.; Rahman, M.L.; Sultana, F. Wireless security control system \& sensor network for smoke \& fire detection. In Proceedings of the ICAMS 2010-Proceedings of 2010 IEEE International Conference on Advanced Management Science, Chengdu, China, 9-11 July 2010; Volume 3, pp. 153-157.

32. Tanutama, L.; Atmadja, W. Home Security System with IOT Based Sensors Running on House Infra Structure Platform. In Proceedings of the IOP Conference Series, Earth and Environmental Science, Solo, Indonesia, 13-14 November 2019 ; Volume 426.

33. Lisakov, S.A.; Pavlov, A.N.; Sypin, E.V.; Leonov, G.V. Determination of control points quantity and their location in protected object for high-speed multipoint electro-optical system for fire detection and determine its spatial coordinates. In Proceedings of the International Conference of Young Specialists on Micro/Nanotechnologies and Electron Devices, Erlagol, Russia, 29 June-3 July 2017; pp. 371-377.

34. Grinchenko, B.B.; Kuznetsov, A.V.; Bakanov, M.O.; Tarakanov, D.V. Multi-factor fire dynamics monitoring in textile industry buildings. Izvestiya Vysshikh Uchebnykh Zavedenii, Seriya Teknologiya Tekstil'noi Promyshlennosti 2019, 382, 178-183.

35. Malykhina, G.F.; Guseva, A.I.; Militsyn, A.V. Early fire prevention in the plant. In Proceedings of the 2017 International Conference on Industrial Engineering, Applications and Manufacturing, ICIEAM 2017-Proceedings, St. Petersburg, Russia, 16-19 May 2017.

36. Malykhina, G.F.; Guseva, A.I.; Militsin, A.V.; Nevelskii, A.S. Developing an intelligent fire detection system on the ships. In Proceedings of the CEUR Workshop Proceedings, CEUR-WS, Moscow, Russia, 24-26 November 2017; Volume 2064, pp. 289-296.

37. Khoat, H.T.; Kim, J.T.; Quoc, T.D.; Kwark, J.H.; Ryou, H.S. A numerical analysis of the fire characteristics after sprinkler activation in the compartment fire. Energies 2020, 13, 3099. [CrossRef]

38. Zhu, H.; Shen, Y.; Yan, Z.; Guo, Q.; Guo, Q. A numerical study on the feasibility and efficiency of point smoke extraction strategies in large cross-section shield tunnel fires using CFD modeling. J. Loss Prev. Process Ind. 2016, 44, 158-170. [CrossRef]

39. Maheen, J.B.; Aneesh, R.P. Machine Learning Algorithm for Fire Detection using Color Correlogram. In Proceedings of the 2019 2nd International Conference on Intelligent Computing, Instrumentation and Control Technologies, ICICICT 2019, Kannur, India, 5-6 July 2019; pp. 1411-1418.

40. Gagliardi, A.; Saponara, S. Advised: Advanced video smoke detection for real-time measurements in antifire indoor and outdoor systems. Energies 2020, 13, 2098. [CrossRef]

41. Qiu, X.; Xi, T.; Sun, D.; Zhang, E.; Li, C.; Peng, Y.; Wei, J.; Wang, G. Fire Detection Algorithm Combined with Image Processing and Flame Emission Spectroscopy. Fire Technol. 2018, 54, 1249-1263. [CrossRef]

42. Spurny, V.; Pritzl, V.; Walter, V.; Petrlik, M.; Baca, T.; Stepan, P.; Zaitlik, D.; Saska, M. Autonomous Firefighting Inside Buildings by an Unmanned Aerial Vehicle. IEEE Access 2021, 9, 15872-15890. [CrossRef]

43. Naser, M.Z.; Lautenberger, C.; Kuligowski, E. Special Issue on "Smart Systems in Fire Engineering". Fire Technol. 2021, 57, 2737-2740. [CrossRef]

44. Panev, Y.; Kotsovinos, P.; Deeny, S.; Flint, G. The Use of Machine Learning for the Prediction of fire Resistance of Composite Shallow Floor Systems. Fire Technol. 2021, 57, 3079-3100. [CrossRef]

45. Węrzyński, W.; Krajewski, G.; Kimbar, G. Smart Smoke Control as an Efficient Solution for Smoke Ventilation in Converted Cellars of Historic Buildings. Fire Technol. 2020, 57, 3101-3123. [CrossRef]

46. Richter, E.; Krause, U. Development of solid propellant for the production of fire suppression aerosols. Fire Safety Journal 2021, 120, 103113. [CrossRef]

47. Agafonov, V.V.; Kopylov, S.N.; Sychev, A.V.; Uglov, V.A.; Zhyganov, D.B. The mechanism of fire suppression by condensed aerosols; All-Russian Scientific Research Institute for Fire Protection: Moscow, Russia, 2004; pp. 1-10.

48. Li, G.; Pan, C.; Liu, Y.; Zhu, X.; Ni, X.; Zhao, X.; Chen, G.; Wang, X. Evaluation of the effect of water mist on propane/air mixture deflagration: Large-scale test. Process Saf. Environ. Prot. 2021, 147, 1101-1109. [CrossRef]

49. Volkov, R.S.; Kuznetsov, G.V.; Strizhak, P.A. Analysis of the Characteristics of the Retardation and Entrainment of Droplets in a Polydisperse Water Flow by High-Temperature Gases Under Conditions of Intense Phase Transformations. J. Eng. Phys. Thermophys. 2015, 88, 937-947. [CrossRef] 
50. Volkov, R.S.; Kuznetsov, G.V.; Strizhak, P.A. Criterion expressions for conditions and deceleration and subsequent entrainment of water drops by high-temperature gases. Tech. Phys. 2015, 60, 1310-1315. [CrossRef]

51. Volkov, R.S.; Kuznetsov, G.V.; Stizhak, P.A. The influence of initial sizes and velocities of water droplets on transfer characteristics at high-temperature gas flow. Int. J. Heat Mass Transf. 2014, 79, 838-845. [CrossRef]

52. Lv, D.; Tan, W.; Zhu, G.; Liu, L. Gasoline fire extinguishing by $0.7 \mathrm{MPa}$ water mist with multicomponent additives driven by $\mathrm{CO}_{2}$. Process Saf. Environ. Prot. 2019, 129, 168-175. [CrossRef]

53. Ghiji, M.; Novozhilov, V.; Moinuddin, K.; Joseph, P.; Burch, I.; Suendermann, B.; Gamble, G. A review of lithium-ion battery fire suppression. Energies 2020, 13, 5117. [CrossRef]

54. Erd, A.; Stoklosa, J. Energy Dependencies in Li-Ion Cells and Their Influence on the Safety of Electric Motor Vehicles and Other Large Battery Packs. Energies 2020, 13, 6738. [CrossRef]

55. Zhu, M.X.; Zhu, S.B.; Gong, J.H.; Zhou, Z. Experimental Study on Fire and Explosion Characteristics of Power Lithium Batteries with Surfactant Water Mist. In Proceedings of the Procedia Engineering 8th International Conference on Fire Dcience and Fire Protection Engineering (on the Development of Performance-based Fire Code), Nanjing, China, 27-29 October 2017; Volume 211, pp. 1083-1090.

56. Kong, L.; Li, C.; Jiang, J.; Pecht, M.G. Li-ion battery fire hazards and safety strategies. Energies 2018, 11, 2191. [CrossRef]

57. Guo, Q.; Ren, W.; Zhu, J.; Shi, J. Study on the composition and structure of foamed gel for fire prevention and extinguishing in coal mines. Process Saf. Environ. Prot. 2019, 128, 176-183. [CrossRef]

58. Tang, Z.; Xu, G.; Yang, S.; Deng, J.; Xu, Q.; Chang, P. Fire-retardant foam designed to control the spontaneous combustion and the fire of coal: Flame retardant and extinguishing properties. Powder Technol. 2021, 384, 258-266. [CrossRef]

59. Xi, Z.; Wang, X.; Wang, X.; Wang, L.; Li, D.; Guo, X.; Jin, L. Polymorphic foam clay for inhibiting the spontaneous combustion of coal. Process Saf. Environ. Prot. 2019, 122, 263-270. [CrossRef]

60. Zhang, Y.; Lei, B.; Wu, B.; Meng, Y.; He, B. An experimental study on the heat and mass transfer of liquid nitrogen in a loose medium. Energies 2019, 12, 3464. [CrossRef]

61. Lu, Y.; Liu, Y.; Shi, S.; Wang, G.G.X.; Li, H.; Wang, T. Micro-particles stabilized aqueous foam for coal spontaneous combustion control and its flow characteristics. Process Saf. Environ. Prot. 2020, 139, 262-272. [CrossRef]

62. Xi, X.; Shi, Q.; Jiang, S.; Zhang, W.; Wang, K.; Zhengyan, W. Study on the effect of ionic liquids on coal spontaneous combustion characteristic by microstructure and thermodynamic. Process Saf. Environ. Prot. 2020, 140, 190-198. [CrossRef]

63. Xu, Y.; Wang, D.; Wang, L.; Zhong, X.; Chu, T. Experimental research on inhibition performances of the sand-suspended colloid for coal spontaneous combustion. Saf. Sci. 2012, 50, 822-827. [CrossRef]

64. Sheng, Y.; Jiang, N.; Lu, S.; Wang, Q.; Zhao, Y.; Liu, X. Study of Environmental-Friendly Firefighting Foam Based on the Mixture of Hydrocarbon and Silicone Surfactants. Fire Technol. 2020, 56, 1059-1075. [CrossRef]

65. Yu, X.; Jiang, N.; Miao, X.; Li, F.; Wang, J.; Zong, R.; Lu, S. Comparative studies on foam stability, oil-film interaction and fire extinguishing performance for fluorine-free and fluorinated foams. Process Saf. Environ. Prot. 2020, 133, 201-215. [CrossRef]

66. Sivrikaya, E.; Iyigun, B.; Tekin, M.; Kivrak, M.F.; Cavdar, E.; Diker, C.; Ozfidan, O.; Kucuk, S. National legislation and international standards for fire detection and protection systems for industrial transformers and substations of industries facilities. In Proceedings of the 6th International Conference on Electrical and Electronics Engineering (ICEEE 2019), Istanbul, Turkey, 16-17 April 2019; pp. 251-257. [CrossRef]

67. Yan, J.; Xuze, Z.; Yue, W. Research on Intelligent Firefighting Robot in Transformer Substation Based on Water Mist Technology. In Proceedings of the 2020 5th International Conference on Smart Grid and Electrical Automation, ICSGEA 2020, Zhangjiajie, China, 13-14 June 2020; pp. 134-139.

68. Sazzad Sayyed, A.Q.M.; Hasan, M.T.; Mahmood, S.; Hossain, A.R. Autonomous Fire Fighter Robot Based on Image Processing. In Proceedings of the 2019 IEEE Region 10 Symposium, TENSYMP 2019, Kolkata, India, 7-9 June 2019; pp. 503-507.

69. Rodriguez-Sanchez, M.C.; Fernández-Jiménez, L.; Jiménez, A.R.; Vaquero, J.; Borromeo, S.; Lázaro-Galilea, J.L. HelpresponderSystem for the security of first responder interventions. Sensors 2021, 21, 2614. [CrossRef] [PubMed]

70. Sakita, Y. Study on the use of water gun and other fire protection systems for fires in cultural heritage buildings based on example analysis and consideration. Bull. Jpn. Assoc. Fire Sci. Eng. 2017, 67, 69-75. [CrossRef]

71. Zorina, K.; Vasilieva, M.; Babikov, I.; Tanklevskiy, A. Comparison of technical-economic performance of traditional and innovational sprinkler extinguishing units. In Proceedings of the MATEC Web of Conferences International Scientific Conference on Energy, Environmental and Construction Engineering, Saint-Petersburg, Russia, 19-20 November 2018; Volume 245.

72. Das, S.; Dhar, A.; Das, A.; Gayen, P.K.; Pal, B.; Biswas, P. Design and development of fire fighting system using hot redundant PLC in COVID situation. In Proceedings of the Journal of Physics: Conference Series. International Online Conference on Engineering Response to COVID-19, Kalyani, West Bengal, India, 8-9 October 2021; Volume 1797.

73. Shrigondekar, H.; Chowdhury, A.; Prabhu, S.V. Performance by Various Water Mist Nozzles in Extinguishing Liquid Pool Fires. Fire Technol. 2021, 57, 2553-2581. [CrossRef]

74. Shrigondekar, H.; Chowdhury, A.; Prabhu, S.V. Performance of water mist system with base injection in extinguishing small container fires. J. Loss Prev. Process Ind. 2021, 71, 104448. [CrossRef]

75. Wang, Z.; Wang, W.; Wang, Q. Optimization of water mist droplet size by using CFD modeling for fire suppressions. J. Loss Prev. Process Ind. 2016, 44, 626-632. [CrossRef] 
76. Zhu, J.; Li, W.; Lin, D.; Cheng, H.; Zhao, G. Intelligent Fire Monitor for Fire Robot Based on Infrared Image Feedback Control. Fire Technol. 2020, 56, 2089-2109. [CrossRef]

77. Guo, J.; Hou, Z.; Xie, X.; Yao, S.; Wang, Q.; Jin, X. Faster R-CNN Based Indoor Flame Detection for Firefighting Robot. In Proceedings of the 2019 IEEE Symposium Series on Computational Intelligence, SSCI 2019, Xiamen, China, 6-9 December 2019; pp. 1390-1395.

78. Li, M.; Jiang, Y.; Wu, Z.; Fan, R. Real-Time Prediction of Smoke Spread Affected by Multiple Factors in Subway Tunnel Using CAERES-DNN Model. Fire Technol. 2021, 57, 2025-2059. [CrossRef]

79. Zhang, D.; Guo, Z. Mobile Sentry Robot for Laboratory Safety Inspection Based on Machine Vision and Infrared Thermal Imaging Detection. Secur. Commun. Netw. 2021, 2021, 6612438. [CrossRef] 